\title{
Author Correction: Preschool children and chimpanzees incur costs to watch punishment of antisocial others
}

Natacha Mendes, Nikolaus Steinbeis, Nereida Bueno-Guerra, Josep Call and Tania Singer (D)

Correction to: Nature Human Behaviour https://doi.org/10.1038/s41562-017-0264-5, published online 18 December 2017.

In the version of this Article originally published, in Fig. $2 \mathrm{c}$ the hatching indicating antisocial behaviour was on the wrong data bars. This has now been corrected in the Article.

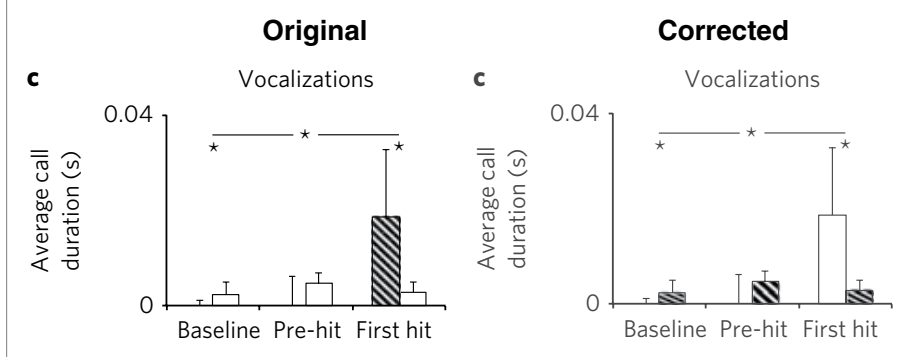

Fig. 2c | Original and corrected. The corrected version has the hatching on the three smaller data bars. 